\title{
Sexual Coercion by Male Chimpanzees Shows That Female Choice May Be More Apparent than Real
}

\section{Citation}

Muller, Martin N., Melissa Emery Thompson, Sonya M. Kahlenberg, and Richard W. Wrangham. 2011. Sexual coercion by male chimpanzees shows that female choice may be more apparent than real. Behavioral Ecology and Sociobiology 65(5): 921-933.

\section{Published Version}

doi:10.1007/s00265-010-1093-y

\section{Permanent link}

http://nrs.harvard.edu/urn-3:HUL.InstRepos:8301595

\section{Terms of Use}

This article was downloaded from Harvard University's DASH repository, and is made available under the terms and conditions applicable to Open Access Policy Articles, as set forth at http:// nrs.harvard.edu/urn-3:HUL.InstRepos:dash.current.terms-of-use\#OAP

\section{Share Your Story}

The Harvard community has made this article openly available.

Please share how this access benefits you. Submit a story.

Accessibility 

\& Richard W. Wrangham ${ }^{3}$

$16{ }^{1}$ Department of Anthropology, University of New Mexico, MSC 1040-01, Albuquerque,

17 New Mexico 87131, USA

$18{ }^{2}$ Department of Biology, Bates College, Lewiston, Maine 04240, USA

$19{ }^{3}$ Department of Human Evolutionary Biology, Harvard University, Cambridge,

20 Massachusetts 02138, USA

22 *To whom correspondence should be addressed.E-mail: muller@unm.edu 


\section{Abstract}

24 The extent to which active female mating preferences influence male reproductive

25 success in mammals is unclear, particularly for promiscuously breeding species like

26 chimpanzees (Pan troglodytes). Previous studies from multiple long-term study sites have

27 shown that female chimpanzees mate more restrictively around ovulation, and this has

28 been taken as evidence for female choice. However, none of these studies rigorously

29 evaluated the alternative hypothesis, that restrictive mating results not from unconstrained

30 choice, but in response to coercive mate guarding, in which males use punishment and

31 intimidation to reduce female promiscuity and promote their own mating interests. Nor

32 did they consider evidence for the potential genetic or phenotypic benefits that females

33 might be choosing. Using 11 years of data from the Kanyawara community in Kibale

34 National Park, Uganda, we previously demonstrated that males achieve elevated mating

35 success with those females toward whom they direct high levels of aggression. Here we

36 extend those findings to show that even female copulatory approaches, which have

37 previously been attributed to female choice, may be influenced by male aggression.

38 Specifically, individual females at our site initiated periovulatory copulations most

39 frequently with the males who were most aggressive toward them throughout their cycles.

40 Those males showed high rates of aggression toward females throughout estrus, despite

41 achieving high copulation rates, demonstrating a continuing conflict of interest over the

42 exclusivity of mating access. Because sexual coercion is potentially widespread in

43 primates and other mammals, we conclude that male aggression must be taken into

44 account before mating preferences can be inferred from female behaviour. 
$47 \quad$ Key Words

48 Female choice, sexual coercion, coercive mate guarding, mating preferences, mixed

49 mating strategy 
Introduction

$51 \quad$ Females in a broad range of species, especially birds, are known to choose mates

52 that offer genetic or phenotypic benefits (Andersson 1994, Hill 2006, Mays et al. 2008).

53 Female choice is less well understood in mammals (Clutton-Brock \& McAuliffe 2009).

54 Because most mammals are polygynous and rarely provide paternal care, male-male

55 competition for access to females is relatively intense. Consequently males that are

56 successful at mating tend to be high quality, which reduces the benefits of active female

57 choice (Clutton-Brock \& McAuliffe 2009). Moreover, intense male mating competition

58 can select for both armaments and large body size, which males of some species employ

59 to constrain female mating behavior (Smuts \& Smuts 1993, Clutton-Brock \& Parker

60 1995, Muller \& Wrangham 2009).

61 Primates present additional difficulties for the assessment of female choice.

62 Because female primates have slow life histories and produce relatively few offspring,

63 mate selectivity is expected to be particularly important in this order (Kappeler \& van

64 Schaik 2004). Yet in many non-human primates, females mate promiscuously by actively

65 soliciting copulations from multiple partners (Dixson 1998, Hrdy 1981, Nunn 1999,

66 Zinner et al. 2004, Clarke et al. 2009). Multi-male mating appears to benefit females

67 primarily by confusing paternity, and thus reducing the risk of male infanticide (Hrdy

68 1979, van Noordwijk \& van Schaik 2000, Paul 2002, van Schaik et al. 2004).

69 Given these problems, the extent and nature of female choice in promiscuously

70 mating primates is uncertain. However, there has been considerable interest in the idea

71 that a promiscuous strategy predominates only in the early follicular phase, when

72 conception is unlikely to occur, and that females exert a preference for particular males 
73 around the time of ovulation, subtly attempting to concentrate paternity in those

74 individuals (Nunn 1999, van Schaik et al. 2004, Clarke et al. 2009). Female choice of

75 high-ranking males has been predicted in this context on the premise that those males

76 would provide the best defence against infanticide (Nunn 1999, van Schaik \& Janson

77 2000, van Schaik et al. 2004, Clarke et al. 2009). Genetic benefits are also possible (Paul

78 2002, Byers \& Waits 2006).

79 The prediction of biased mating during the periovulatory period (POP) has been

80 supported by the only empirical tests to date, from data on wild chimpanzees (Pan

81 troglodytes) (Matsumoto-Oda 1999; Stumpf \& Boesch 2005, 2006; Pieta 2008).

82 Chimpanzees offer a relevant test because females copulate more than 500 times per

83 conception, normally mating with all of the adult males in their community (Wrangham

84 2002). Moreover, infanticide by adult males within the social group is an important risk

85 for females (Nishida \& Kawanaka 1985, Arcadi \& Wrangham 1999, Murray et al. 2007).

86 In the first study, at Mahale (Tanzania), Matsumoto-Oda (1999) found that the

87 proportion of a female's copulations with high-ranking males increased significantly

88 during the POP. She inferred from this result that females preferred to mate with high-

89 ranking males when they were likely to conceive. However her data cannot discriminate

90 between the hypothesis of female choice and the alternative hypothesis of female

91 constraint, i.e. that high-ranking males guard females more intensely during the POP and

92 thereby restrict female options. In support of the female-constraint hypothesis,

93 solicitations by adolescent males (who were low ranking) were more likely to succeed

94 when higher-ranking males were absent ( $34 / 48$ attempts, i.e. $70.8 \%$ success) than when

95 they were present (6/23, i.e. 26.1\%) (Table 5 in Matsumoto-Oda 1999). 
In more detailed studies, Stumpf and Boesch $(2005,2006)$ examined mating

97 patterns in two communities of wild chimpanzees living in Taï National Park (Ivory

98 Coast), quantifying female "preferences" by establishing rates of proceptivity (female-

99 initiated sexual behaviour) and resistance (avoidance of male solicitations) across male-

100 female dyads. They reported that males whose sexual advances were generally resisted by

101 a particular female were resisted by that female at higher rates, and solicited at lower

102 rates, during the POP. No such difference was evident for males who were generally

103 approached by a particular female for copulations.

104 A similar study by Pieta (2008) at our site in Kanyawara, Kibale National Park

105 (Uganda), showed a somewhat different pattern. As at Taï, males whose sexual advances

106 were generally resisted by a particular female were solicited by that female at lower rates

107 during the POP. However, no significant difference was found between rates of resistance

108 in the POP and non-POP. Additionally, and distinct from Taï, males at Kanyawara who

109 were generally approached by a particular female for copulations, were approached by

110 that female at higher rates, and resisted at lower rates, during the POP.

111 Both Stumpf and Boesch $(2005,2006)$ and Pieta (2008) construed their findings

112 as strong evidence for female choice in chimpanzees. However, neither study rigorously

113 tested the alternative hypothesis, that the distribution of female copulatory approaches

114 during the POP (when females were most attractive) was constrained by male aggression

115 (Muller et al. 2009a). For example, even if a female's objective were to solicit all of the

116 males in a group equally, she might be thwarted by the efforts of a coercive male

117 interested in monopolizing her. Measures of female resistance were similarly difficult to

118 interpret. Although chimpanzee females might avoid a male's advances owing to 
119 negative preference, they might also do so because mating could invite punishment from

120 a higher-ranked suitor (Muller et al. 2009a). This is particularly problematic because both

121 studies defined resistance according to a female's initial response to the male solicitation

122 (including "ignoring the solicitation, avoiding the male, screaming, or leaving", Stumpf

$123 \&$ Boesch, 2005). Thus, a female who waited for a high-ranking male to turn his

124 attention elsewhere before mating furtively with a soliciting male would have been

125 classified as "resistant". Problems inherent in these assumptions of preference are

126 illustrated by the fact that in both Stumpf (2004: Appendix B) and Pieta's (2008: Table 1)

127 studies, some females simultaneously "preferred" males based on measures of proceptive

128 behavior whom they "eschewed" based on measures of resistant behavior.

129 Controlling for the potential effects of male behavior on female mating decisions

130 is critical, because much evidence suggests that chimpanzee males use aggression as a

131 coercive mating tactic, making some females more likely to mate with them and less

132 likely to mate with rivals (Muller et al. 2007). For example, we have previously shown

133 that Kanyawara females experience increased rates of male aggression during periods of

134 maximal swelling (i.e. during estrus, Muller et al. 2007), when conception is most likely

135 to occur (Emery Thompson 2005). Parous females, who are more attractive to males

136 (Tutin 1979, Wrangham 2002, Muller et al. 2006), receive higher rates of male

137 aggression during maximal swelling than do less attractive nulliparous females (Muller et

138 al. 2007). Finally, individual males exhibit increased copulation rates with the parous

139 females toward whom they are most aggressive (Muller et al. 2007). This correlation may

140 partly result from females being compelled to copulate more frequently with their

141 aggressors (“direct coercion”), but it also seems likely to reflect a dynamic in which 
142 aggressive males are able to prevent females from mating with other males ("indirect

143 coercion") (Muller et al. 2009a).

144 We have also established that male aggression imposes significant costs on

145 Kanyawara females. Physical injury, including severe wounding, is a regular outcome of

146 the prolonged attacks that are sometimes directed at females (Muller et al. 2009a).

147 Furthermore, levels of stress hormones (cortisol) in females show dramatic increases

148 during periods of cycling and maximal swelling (Muller et al. 2007), a pattern that we

149 have recently shown is driven by an increase in male aggression during these periods

150 (Emery Thompson et al. 2010).

151 To date, attempts to control for the possible influence of male coercion on female

152 choice have mostly focused on the immediate context of mating. It is clear, however, that

153 chimpanzee males rarely use force directly in the act of copulation (Goodall 1986,

154 Stumpf \& Boesch 2006). Stumpf and Boesch (2005), for example, reported no

155 significant correlation between rates of male aggression toward females and rates of

156 female proceptivity during the POP, and concluded that male coercion could therefore not

157 have been responsible for the more restrictive mating pattern at that time. This approach

158 assumes a priori that female behavior is not affected by previous social interactions with

159 males.

160 A growing body of evidence, however, suggests that sexual coercion in primates is

161 often a long-term strategy that achieves its goal by manipulating the future, rather than

162 simply the immediate behavior of the victim (Wrangham \& Muller 2009). Male

163 punishment of both female mating resistance (Clutton-Brock \& Parker 1995) and female

164 promiscuity (Clarke et al. 2009) can be effective strategies if females modify their 
165 behavior in response to the actions of known males. The development of this response is

166 evident when female hamadryas baboons (Papio hamadryas hamadryas) are first

167 incorporated into a one-male unit (Swedell \& Schreier 2009). Male hamadryas employ

168 aggression to enforce female proximity, promoting their long-term social bond. Once a

169 bond is established, and females learn to follow a male, and to avoid rival males, rates of

170 aggression drop (Swedell \& Schreier 2009). Such a resolution may not occur, however, if

171 male and female mating interests are in conflict, or if threats to male mating exclusivity

172 emerge. For example, in mountain gorillas, encounters with strange males often provoke

173 aggression by resident silverbacks against their mates (Sicotte 1993).

174 Because chimpanzees, like hamadryas baboons, live in stable social networks and

175 exhibit cognitive abilities such as individual recognition, memory of specific events, and

176 sophisticated learning (Goodall 1986), male aggression might in theory affect female

177 behavior over the long term. We have previously shown that males in Kanyawara who

178 direct high levels of aggression toward individual females show increased rates of

179 copulation with those females compared to other males. We have also shown that the

180 majority of POP copulations are initiated by males rather than females (Emery Thompson

181 \& Wrangham 2008). Nevertheless, it remains possible, as suggested by Stumpf and

182 Boesch $(2005,2006)$ that the copulations initiated by females represent a free expression

183 of preference. Here we employ 11 years of data from Kanyawara, to test whether patterns

184 of female-initiated copulation during the POP (when conception is most likely) reflect

185 primarily male coercion or female attempts to bias paternity toward specific males.

186 Because females might choose males based on a range of criteria, we consider predictions

187 for phenotypic and genetic benefits separately (See Table 1). 
In theory females might practice unfettered promiscuity to gain protection from

189 infanticide, giving all males a more or less equal probability of conception. However,

190 previous work at Kanyawara suggests that this does not occur. For example, high-ranking

191 males at Kanyawara show higher rates of copulation with females during the POP, and

192 females show increased copulation rates with aggressors relative to non-aggressors

193 (Emery Thompson \& Wrangham 2008; Muller et al. 2007). It is thus necessary to

194 consider alternative hypotheses to explain these biased mating patterns.

195 If females are actively concentrating paternity in particular males to gain

196 protection from infanticide (van Schaik et al. 2000), then all females are expected to

197 initiate periovulatory copulations most frequently with the alpha male (van Schaik et al.

198 2004). Consequently, the alpha is expected to show decreased rates of male-female

199 aggression during the POP, since his interest in sequestering females from competitors is

200 aligned with the female goal of concentrating paternity (Muller et al. 2009ab).

201 If female mate choice is directed toward maximizing genetic quality, then

202 predictions differ depending on whether females are choosing males with "good genes"

203 or males with "compatible genes" (Mays \& Hill 2004, Neff \& Pitcher 2005). In "good

204 genes" models, females choose mates based on a particular combination of alleles, and

205 females within a community are expected to bias paternity toward the same male or

206 males (as in pronghorn, Antilocapra americana: Byers \& Waits 2006). In contrast to the

207 predictions of the infanticide-avoidance hypothesis, this male need not be the alpha (e.g.

208 female preference for brightly colored males in mandrills, Mandrillus sphinx: Setchell

209 2005). If females are choosing males based on genetic compatibility (i.e. dissimilarity),

210 then females are not expected to bias paternity toward the same males (e.g. potential 
211 cryptic choice in the grey mouse lemur, Microcebus murinus: Schwensow et al. 2008). In

212 both models, males who are the targets of paternity concentration are expected to show

213 decreased rates of male-female aggression during the POP, since their interests are

214 aligned with those of the females.

215 If biases in female sexual initiations reflect constraints imposed by male

216 aggression, then females should solicit periovulatory copulations most frequently from

217 the males who are most aggressive toward them (Muller et al. 2007, 2009a). Such skew

218 could reflect direct coercion (a male increasing his absolute mating success with a

219 female), indirect coercion (a male restricting a female's ability to solicit other males), or

220 both. Furthermore, if biases in female copulatory initiations result from male constraints

221 on female promiscuity, and not female interest in paternity concentration, then conflict of

222 interest between males and females is expected to continue during the POP, as females

223 continue attempting to mate with males other than the aggressor. Consequently, rates of

224 male aggression against females are expected to remain steady or intensify around

225 ovulation. Finally, if biases in female copulatory initiations reflect primarily male mate

226 guarding (indirect coercion), then females are expected to show increased solicitation

227 rates toward males in the absence of the males who are most aggressive toward them.

229 Methods

230 Study population and long-term data

231 The subjects of the study were members of the Kanyawara community in Kibale

232 National Park, Uganda, a chimpanzee population that has been studied continuously since

233 1987. This study incorporates data from 29,488 observation hours from January 1996 to 
234 December 2006. The community consisted of 47 chimpanzees at the beginning of the 235 study (including 11 adult males and 17 adult females) and 52 individuals at the end of the

236 study (including 10 adult males and 16 adult females).

237 Behavior was recorded by a team of observers, which normally consisted of 2-3

238 long-term Ugandan field assistants and 1-2 university-based researchers (graduate

239 students, postdoctoral researchers, or one of the authors). Confidence in the accuracy of

240 long-term behavioral data comes from tests documenting close agreement between focal

241 data collected by researchers and all-occurrence sampling data collected independently

242 by field assistants (Muller et al. 2007), together with routine measures of inter-observer

243 reliability (Kibale Chimpanzee Project, unpublished data).

244 Chimpanzees were located by following their tracks, listening for calls or waiting

245 near fruiting trees. Whenever possible, observers followed chimpanzees from the time

246 that they woke in the morning until they constructed their night nests. Observers

247 identified all individuals present in a focal party at 15 min intervals throughout the day. A

248 party was defined as all chimpanzees within 50 continuous meters of each other.

249 Observers also detailed the behavior of individual party members during $10 \mathrm{~min}$ focal

250 sessions. Focal targets consisted of all age-sex classes, and were randomly selected

251 throughout the day from observable party members. Observers attempted to record all

252 overt submissive vocalizations (pant-grunts) and behaviors, and any aggression that

253 occurred within the party, including the identities of the actors.

254 Aggression was defined as any directed charge, chase or attack (see Muller 2002

255 for definitions). These types of aggression are accompanied by exaggerated movements

256 and vocalizations (e.g. screams) from victims, rendering them highly conspicuous to 
257 observers. Thus, our sampling of aggression is equivalent to all-occurrence sampling

258 (Altmann 1974). Nevertheless, the long-term data underestimate true rates of aggression,

259 because some interactions are obscured by vegetation. Muller et al. (2007) compared

260 focal data on intersexual aggression collected by a single observer with long-term data

261 and showed that these underestimates represent an unbiased sample of the behavior.

262 Dyadic rates of male-female aggression are reported from three different time

263 periods. "POP aggression" was calculated by summing the number of charges, chases and

264 attacks a male directed at a female across all POP days (see definition below), and

265 dividing by the number of hours the pair were observed together on those days. "Pre-POP

266 aggression" was calculated in the same manner, but for days of maximal swelling prior to

267 the POP. "Cycling aggression" was the same measure again, but calculated over all days

268 in which the female was actively cycling (i.e. not pregnant or experiencing lactational

269 amenorrhea), regardless of whether she was maximally swollen on that day. Thus, all

270 aggression rates controlled for dyadic association times, which are reported in Tables 2

271 and 3.

272 Male dominance ranks were assigned based on the direction of submissive

273 vocalizations (pant-grunts) and decided agonistic encounters among male dyads (Muller

$274 \&$ Wrangham 2004). Ordinal ranks (r) were assigned to each male on a yearly basis, and

275 these were standardized by the number of adult males in the hierarchy $\left(\mathrm{n}_{\mathrm{M}}\right)$ using the

276 formula: $\left(n_{M}-r\right) /\left(n_{M}-1\right)$. Each male was assigned a mean rank over the period of female

277 sexual cycling sampled, based on these standardized yearly ranks.

278

279 Ovarian cycle data 
Observers used a simple scale to record the degree of tumescence of the sexual

281 swelling for each female in a party. Females with sexual skins that were completely flat

282 received scores of 1 . Females with sexual skins that were partially inflated (i.e. soft

283 and/or wrinkled rather than tense and shiny) received scores of 2. Females with sexual

284 skins that were maximally tumescent (i.e. tense and shiny with no drooping) received

285 scores of 3. Estrous females were defined as having maximally tumescent swellings.

286 Nonestrous females were those with partial or flat swellings.

287 In wild chimpanzees, ovulation occurs within the period of maximal swelling

288 tumescence and, according to independent examinations of ovarian cycle profiles, is most

289 probable (>75\%) between 2 and 5 days before the end of swelling, designated D-2 to D-5

290 if D0 is the first day of detumescence (Deschner et al. 2003; Emery Thompson 2005;

291 Emery Thompson \& Wrangham 2008). Because mammalian sperm are predicted to

292 survive in the female reproductive tract for approximately 48-72 hours (Johnson and

293 Everitt, 1988; Royston, 1982; Wilcox et al. 1995), these models also assign a high

294 probability of fertile mating to cycle days D-6 and D-7. Thus, we define the probable

295 periovulatory period (POP) as days D-2 to D-7. Days of low fertilization potential (non-

296 POP) included the last day of sexual swelling when ovulation probability is low and

297 female attractiveness drops substantially (Emery Thompson \& Wrangham 2008) and up

298 to 10 pre-POP days with maximal swelling tumescence. We excluded both cycles from

299 females known to be pregnant (from hCG testing or other hormonal data), and cycles for

300 which the first day of maximal swelling or the day of detumescence were not observed

301 (Emery Thompson 2005).

302 We limited our analyses to interactions between adult males (aged 15 years and 
303 over) and parous females. Nulliparous female chimpanzees experience both a prolonged

304 period of subfecund cycling following menarche, and relatively high rates of neonatal

305 mortality (Roof et al. 2005, Brewer-Marsden et al. 2006). Consequently, males prefer

306 parous females as mates, and compete more intensely for access to them (Muller et al.

307 2006). Table 4 shows, for each female, the number of cycles sampled in both POP and

308 non-POP periods.

309

$310 \quad$ Female proceptivity

311 Chimpanzee copulations are normally initiated by a clear solicitation from either

312 the male or the female (Goodall 1986). Male courtship behaviour includes direct gaze,

313 branch shaking, bipedal swagger, knuckle-rapping, or outstretched arms, all accompanied

314 by penile erection. Female solicitations normally consist of a female approaching a male

315 and crouching with her sexual swelling toward him. Copulation was defined as mounting

316 with intromission and pelvic thrusting (Wrangham 2002). We have omitted cases where

317 observers could not determine who initiated the copulation. This produced a total of 996

318 copulations in non-pregnant cycles with known POP dates.

319 Following Stumpf and Boesch (2005) and Pieta (2008), we assigned each male to

320 one of three categories for each female, depending on whether he was generally solicited

321 by that female for copulation. "Approached" males were those whose average solicitation

322 rate by a female, during periods of maximal swelling, exceeded that female's mean rate

323 of male solicitation by at least $25 \%$. "Non-approached" males were those who fell below

324 a female's mean solicitation rate by at least $25 \%$. All other males were designated

325 "Neutral." We favour these terms over Stumpf and Boesch's "Preferred" and "Non- 
326 preferred" males, because they describe behaviour without attributing motivation.

327 Proceptivity rates were calculated for each male-female dyad by dividing the number of

328 female-initiated POP copulations by the number of hours the pair were observed together

329 during the POP.

330 Previous chimpanzee studies have employed rates of "resistance" (defined as

331 ignoring a male solicitation or actively avoiding a copulation attempt) as an additional

332 measure of female choice (Stumpf \& Boesch 2005, Pieta 2008). For three reasons we did

333 not incorporate resistance in the present study. First, Pieta's (2008) data show that, at

334 Kanyawara, female proceptivity rates showed larger and more reliable changes during the

335 POP than did rates of resistance. Second, active female resistance of male copulatory

336 attempts (i.e. screaming at and fleeing from, struggling with, or striking a male) is rare

337 enough to be of questionable significance as an effective mode of female choice ( $4 \%$ at

338 Gombe: Goodall 1986; 3\% overall rate at Kanyawara: Kibale Chimpanzee Project,

339 unpublished data). In the current dataset (which is limited to fully adult males and non-

340 pregnant cycles) fewer than $1.2 \%$ of POP copulations were actively resisted by females

$341(\mathrm{n}=5)$, making it impossible to establish meaningful patterns. Third, the operational

342 definition of resistance is problematic, with rates recorded by different observers varying

343 markedly within sites. At Taï, for example, Boesch \& Boesch-Achermann (2000)

344 reported a rate of $8 \%$, whereas Stumpf \& Boesch (2005) reported 28\%. Similar

345 differences are seen between resistance rates in the long-term data at Kanyawara, and

346 those reported by Pieta (2008). At Kanyawara, the lower rates reflect active resistance by

347 females. The higher rates reported by Pieta can only be generated by classifying females

348 who initially ignore a male's solicitation as resistant, whether or not they later copulate 
349 with him. As discussed previously, this assumption results in behaviors that may have

350 nothing to do with negative preference being classified as resistant (e.g. if a female delays

351 her positive response to a male's solicitation until the attention of a high-ranking male is

352 directed elsewhere).

353 Interpreting female resistance is further complicated by the fact that a female may

354 ignore or even flee from a male because she does not want to mate with him, but also out

355 of anxiety -- male solicitations frequently include moderately aggressive behaviours such

356 as branch shaking, foot stomping, and piloerection -- or from fear of another male nearby.

357 At Kanyawara we sometimes see females fleeing male copulatory approaches following

358 threats from nearby males. These observations are consistent with the hypothesis that

359 male coercion in this species functions to constrain female mating behavior (Muller et al.

360 2006). In practice, a female's motivation can be impossible to determine. This difficulty

361 may explain inconsistencies in prior choice studies, which reported some females having

362 both high proceptivity and high resistance rates to the same male (Stumpf \& Boesch

363 2005, Pieta 2008).

364

365 Analyses

366 Dyadic rates of male-female aggression during cycling and rates of copulation

367 (both overall and female-initiated) during the periovulatory period (POP), were compared

368 for 8 females and 12 males using the Kr row-wise matrix partial correlation test

369 (Hemelrijk 1990). Because our data span multiple years, it was impossible for some

370 individuals in the dataset to interact (e.g., if a female had died before a male entered

371 adulthood). Consequently, there were missing values in our matrices ( $25 \%$ of 96 cells). 
372 To deal with such values, we created a third matrix containing dummy variables -- zero

373 for non-missing values, and a constant for missing values (Hemelrijk 1990). The constant

374 was also added to missing values within the aggression and copulation matrices, and the

375 dummy matrix was then partialled out. Statistics were calculated using Matman 1.1

376 software (Noldus Information Technology, Wageningen, The Netherlands). Significance

377 of the correlation coefficient was estimated with 2,000 permutations.

378 All other statistical analyses were conducted using SPSS 16.0 (SPSS Inc., Chicago,

379 IL, U.S.A.) Comparisons between dependent groups employed the Wilcoxon signed-rank

380 test. All correlations report Kendall's rank correlation coefficient $(\tau)$. All statistical tests

381 are two tailed, and means are reported \pm s.e.

382

383 Results

384 Proceptivity rates varied across females. Average rates of female proceptivity

385 across the adult males ranged from 0.005 to 0.014 times per hour for all periods of

386 maximal swelling (mean: $0.01 \pm 0.002$ ). These figures are comparable to those reported

387 by Stumpf and Boesch (2005). On average, females initiated $28.4 \%$ of their copulations

388 with males (female range: $19.6-47.4 \%$; $\mathrm{n}=8$ parous females; $\mathrm{stdev}=8.91$ ) whereas male

389 initiation accounted for, on average, $71.6 \%$ of copulations.

$390 \quad$ Patterns of female proceptivity during estrus are summarized in Table 5, which

391 shows approached, non-approached and neutral males for each female. The alpha male

392 (MS) is a conspicuous outlier in these data, as he was classified as approached for all of

393 the parous females in our sample. For ranks below alpha, there was no consistency

394 among females as to which males received high rates of proceptivity, and which went 
unsolicited. Every male except the alpha was categorized as non-approached by at least

396 one female, and every male except the lowest-ranking individual was classified as

397 approached by at least one female. Figure 1 shows, for each male, the absolute number of

398 females for whom he was an approached or non-approached male. Neither of these

399 measures correlated with average male rank across the study period (Kendall correlation;

400 approached: $\tau=0.287, \mathrm{p}=0.220, \mathrm{n}=12 ;$ non-approached: $\tau=-0.097, \mathrm{p}=0.674, \mathrm{n}=12$ ).

401 It was necessary to use mean male rank for statistical purposes, but it should be

402 noted that the lack of an association between male rank and approach preference cannot

403 be explained by male ranks changing over the study period (e.g. if a male interacted with

404 one estrous female while low-ranking and another while high-ranking). Our results were

405 similar for the subset of males ( $\mathrm{n}=6$ ) who remained high- (MS, BB), medium- $(\mathrm{BF})$, or

406 low-ranking (YB, PG, SY) throughout the study period.

407 Counter to the predictions of hypotheses based on active female paternity

408 concentration, the alpha male (MS) showed no decrease in aggression toward estrous

409 females during the POP compared to pre-POP days of maximal swelling (Figure 2). On

410 average, parous females received aggression from the alpha male $0.0183 \pm 0.009$ times

411 per hour during the POP. This rate was marginally higher than that on non-POP days of

412 maximal swelling $(0.0166 \pm 0.004$ times per hour $)$, but the difference was not statistically

413 significant (Wilcoxon signed ranks test: $\mathrm{Z}=-0.105, \mathrm{p}=0.917, \mathrm{n}=8$ parous females).

414 Similarly, individual approached males showed no difference in rates of

415 aggression, between POP and pre-POP days of maximal swelling, directed toward the

416 females who solicited copulations from them at high rates (Figure 2). On average, parous

417 females received aggression from their approached males $0.0102 \pm 0.003$ times per hour 
418 during the POP. This was identical to the rate on non-POP days of maximal swelling

$419(0.0102 \pm 0.003$ times per hour; Wilcoxon signed ranks test: $Z=-0.14, p=0.889, n=8$

420 parous females).

421 Consistent with the coercion hypothesis, when females were most likely to

422 conceive (i.e. during the POP), they initiated copulations most frequently with the males

423 who were most aggressive toward them throughout periods of ovarian cycling. A matrix

424 partial correlation procedure (Hemelrijk 1990) revealed a significant positive association

425 between the amount of aggression directed by males at individual parous females during

426 all periods when they were cycling, and the number of times females approached those

427 males for copulation during the POP $\left(\tau_{\mathrm{rw} ; \mathrm{xy} \cdot \mathrm{z}}=0.37, \mathrm{p}<0.001, \mathrm{n}=8\right.$ females, 12 males $)$.

428 There was also a significant positive association between the amount of aggression

429 directed by males at individual cycling females and the number of times females

430 copulated with those males during the POP, regardless of who initiated the copulation

$431\left(\tau_{\mathrm{rw} ; \mathrm{xy} . \mathrm{z}}=0.32, \mathrm{p}=0.001, \mathrm{n}=8\right.$ females, 12 males $)$. There was no significant correlation

432 between the amount of aggression directed by males at individual cycling females during

433 the POP and the number of times females copulated with those males during the POP

$434\left(\left(\tau_{\mathrm{rw} ; \mathrm{xy} . \mathrm{z}}=0.106, \mathrm{p}=0.12, \mathrm{n}=8\right.\right.$ females, 12 males $)$.

435 As an additional test of the relationship between male aggression and female

436 proceptivity, we compared, for each of 8 parous females, periovulatory proceptivity rates

437 toward males who were aggressive toward the female at rates above and below the

438 median amount of male aggression received by her (Figure 3). As expected, individual

439 females solicited periovulatory copulations at significantly higher rates from the males

440 that were more aggressive toward them $(0.013 \pm 0.002$ solicitations per hour $)$, than those 
441 who were less aggressive toward them $(0.002 \pm 0.001$ solicitations per hour; Wilcoxon

442 signed rank test: $\mathrm{Z}=-2.52, \mathrm{p}=0.012, \mathrm{n}=8$ females). Strikingly, half of the females in our

443 sample never solicited a periovulatory copulation from any of the males who directed less

444 than the median amount of aggression toward them.

445 Because the alpha male, MS, was both solicited by, and highly aggressive toward,

446 every female in our sample, we wanted to test whether female proceptive behavior

447 changed in his absence. If female promiscuity is constrained by male aggression, in the

448 form of coercive mate guarding, then females are expected to show higher rates of

449 proceptivity when MS is not in a party. Unfortunately, MS was rarely absent when parous

450 females were observed with full swellings. For the eight females in our sample, the mean

451 of mean dyadic association times with males in parties containing MS was 243 hours for

452 periods of maximal swelling. For parties without MS, this figure was only 12 hours. Out

453 of 88 potential adult male/estrous female dyads, 45 were never observed in the absence of

454 MS, and 31 were seen together for less than 8 hours. The remaining 13 dyads all included

455 either AL or NL (the two females with the largest sample of cycles), who were observed

456 with other males in MS's absence for an average of 70 hours per dyad. Looking at the

457 data from these females, a strong effect of the alpha's presence on mating behavior is

458 evident, for both male-initiated and female-initiated copulations. Consistent with the male

459 coercion hypothesis, individual males were solicited by AL and NL at significantly

460 higher rates in parties where MS was absent $(0.039 \pm 0.016$ times per hour) than in

461 parties where he was present $(0.007 \pm 0.002$ times per hour; Wilcoxon signed ranks test:

$462 \mathrm{Z}=-2.366, \mathrm{p}=0.018, \mathrm{n}=8$ males; Figure 4). In turn, males solicited $\mathrm{AL}$ and $\mathrm{NL}$ at

463 significantly higher rates in parties without MS $(0.317 \pm 0.126$ times per hour) than in 
464 parties with him $(0.006 \pm 0.002$ times per hour; Wilcoxon signed ranks test: $Z=-2.366$,

$465 \mathrm{p}=0.018 ; \mathrm{n}=8$ males $)$.

466

\section{Discussion}

468 Our study is the first research on female choice in wild primates to rigorously test

469 for the confounding effects of male aggression on female behavior. Using a larger pool of

470 male mating partners than previous studies, and incorporating more female cycles, we

471 found that female copulatory approaches in chimpanzees are not consistent with

472 unfettered female choice, but instead appear constrained by persistent coercive aggression

473 from males. All the females in our sample showed elevated rates of periovulatory

474 proceptivity toward the alpha male (MS), who became dominant in 1997 and maintained

475 his position through the end of this study in 2006. Each female solicited between one and

476 five additional males at high rates during the POP. The identity of solicited males differed

477 by female, and male rank did not appear to be an important criterion for selection.

478 Although universal proceptivity toward the alpha male might ostensibly support a model

479 of female choice for good genes, and the idiosyncratic distribution of proceptivity toward

480 other males could fit with a model of choice for genetic compatibility, additional

481 observations favor the alternative hypothesis that patterns of female proceptivity

482 primarily reflect male sexual coercion (Wrangham \& Muller 2009).

483 First, the males who were most aggressive toward individual females, not only

484 during periods of maximal swelling, but also in contexts not directly related to mating,

485 were the ones most frequently solicited by those females during the POP. This result

486 explains the systematic bias toward the alpha male since, compared to other males, he 
487 showed high levels of aggression to all of the females in our sample (Muller et al. 2009a).

488 The present data cannot distinguish whether this bias occurs (1) because aggressive males

489 compel females to solicit them more than they would have otherwise, (2) because

490 aggressive males receive a higher relative share of solicitations by reducing the

491 probability that a female will solicit other males, or (3) both. However, the fact that

492 females increased their solicitation rates of all males in the absence of the most

493 aggressive male supports the occurrence of indirect coercion (i.e. coercive mate

494 guarding).

495 Second, patterns of female-directed aggression by the alpha male and other

496 approached males, during periods of maximal swelling, challenge the notion that females

497 are actively concentrating paternity. If, for example, females are eager to bias conceptions

498 toward the alpha male, and the alpha male is concerned with paternity certainty, then the

499 interests of the pair should be aligned during the POP. Consequently, the alpha male

500 should be less aggressive toward females as ovulation approaches, and the females

501 become more compliant, mating primarily with him. The fact that the alpha male at

502 Kanyawara continued to show high rates of female-directed aggression in periods

503 immediately preceding ovulation indicates a conflict of interest. The existence of such

504 conflict suggests that females were resistant to the alpha's mate-guarding efforts, and that

505 they were interested in mating with additional males. This interpretation is further

506 supported by the fact that females showed increased rates of male solicitation when the

507 alpha male was absent. A similar argument applies generally to approached males, who

508 also showed a steady rate of aggression throughout the period of maximal swelling

509 toward the females who solicited them most frequently. 
Although it is possible that males may simply differ in their overall propensity for

511 aggression, and be incapable of modulating their behavior in response to female

512 compliance or resistance, this seems unlikely for two reasons. First, previous studies from

513 Kanyawara have shown that male aggression is elegantly tailored to context. Males are

514 more aggressive toward attractive, parous females than they are toward subfecund,

515 nulliparous females (Muller et al. 2007). Males aggressively interfere in copulations at

516 higher rates in the POP than the non-POP, and exhibit elevated rates of male-male

517 aggression in conceptive vs. nonconceptive cycles (Emery Thompson \& Wrangham

518 2008). Finally, the alpha male, MS, is less likely to aggressively interfere in copulations

519 involving his male allies, than in those involving non-allies (Duffy et al. 2007). Thus, if

520 females are amenable to being mate-guarded by males, there is no reason to suppose that

521 males should not be capable of tempering their aggression in reply.

522 Second, with the exception of the alpha, no individual male in the study was

523 generally aggressive toward all parous females. Males showed variable rates of

524 aggression across potential mating partners, clearly singling out individual females for

525 special consideration. Why a male should focus his coercive efforts on a particular female

526 or females is not clear, but the fact that across male-female dyads, total copulation rates

527 during the POP and rates of male aggression during cycling were correlated, suggests that

528 the strategy is a successful one.

529 Although our data are consistent with the idea that male aggression limits female

530 promiscuity over the long-term, this idea is difficult to test directly. Evidence for such a

531 dynamic in hamadryas baboons is more straightforward, because male-female

532 relationships can be tracked from their inception, and it is clear that male aggression 
533 decreases once females reliably maintain proximity and avoid other males (Swedell \&

534 Schreier 2009). The current chimpanzee study followed ongoing, long-term relationships,

535 so there was no way to show a direct decrease of female promiscuity in response to male

536 aggression. However, the fact that females showed increased proceptivity in the absence

537 of the most aggressive male suggests a distinct dynamic from that of hamadryas, in which

538 females are resistant to male mate guarding. Future studies will examine the evidence for

539 coercive mate guarding more directly by tracking the development of specific male-

540 female relationships from adolescence.

541 Why should a female be resistant toward the mate-guarding efforts of a high-

542 ranking male like the alpha? One possibility is that the cost of acquiescence is high, if it

543 invites intense efforts from other males at direct sexual coercion in the form of

544 intimidation and harassment. Another is that the benefits provided by high-ranking males

545 are few. Male chimpanzees provide little or no direct paternal care. And because female

546 chimpanzees frequently travel alone or in small groups, they regularly encounter

547 potentially infanticidal males in the absence of the alpha (Clarke et al. 2009).

548 Consequently, even high-ranking males may not be able to offer reliable protection from

549 infanticide. The most likely potential benefit to females of biasing paternity toward high-

550 ranking males in fission-fusion species is therefore "good genes." Whether such benefits

551 ever outweigh the risk of infanticide inherent in any attempt to actively concentrate

552 paternity in a single male is an open question.

553 Furthermore, females could conceivably gain the same genetic benefits under a

554 scenario of passive choice, whereby the "best-male" (Clutton-Brock \& Harvey 1976)

555 emerges from the conclusion of male-male competition, mate guarding, and sperm- 
556 competition. Evidence from our site supports the hypothesis that male chimpanzees both

557 detect and respond to changes in female conception risk without behavioral cues (for Taï

558 see Deschner et al. 2004), and that shifting mating dynamics over the cycle can be

559 accounted for primarily by shifts in the competitive investment and solicitation behavior

560 of high-ranking males (Emery Thompson 2005, Emery Thompson \& Wrangham 2008).

561 Even at Taï, where female choice has been argued to be particularly important (Stumpf \&

562 Boesch 2005, 2006), long-term paternity data show a precise fit with the predictions of

563 the priority-of-access model, which posits male dominance status as the primary

564 determinant of mating access (Boesch et al. 2006).

565 The assumption that female chimpanzees should subtly try to realize secret

566 preferences for chosen males makes sense from an anthropocentric perspective, given

567 that women express obvious preferences for certain men over others. However, there is

568 little evidence that chimpanzee females evince this type of mating psychology, or that it

569 would provide a clear evolutionary benefit if they did. If the result of male-male

570 competition for mates, sperm competition, and effective mate guarding were a reliable

571 indicator of male quality in chimpanzees, then attempts by females to thwart these

572 mechanisms via active mate choice would make little sense. And although females might

573 reinforce these mechanisms through active choice, such a strategy would appear not only

574 superfluous, but, in the face of persistent infanticide risk, dangerous. We do not suggest

575 that females are passive players in the chimpanzee mating game. Rather, we acknowledge

576 the possibility that female agency is directed primarily at maximizing offspring survival

577 through a strategy of paternity confusion, and that the evolved mating psychology of

578 female chimpanzees is profoundly different from that of human females. 
The Kanyawara data are thus consistent with either of two conclusions: (1) active

580 female choice is absent, and females instead pursue a strategy of unbiased promiscuity to

581 confuse paternity; (2) female mate preferences exist but are constrained by male-male

582 competition and sexual coercion in this male-dominant species. The data do not support a

583 "mixed" strategy in which females attempt to concentrate paternity in preferred males.

584 Although our study was entirely observational, our results are consistent with the

585 one experimental study conducted on a promiscuous primate (Macaca fascicularis) that

586 gave females complete control over access to males, thus reducing the potential for male

587 coercion (Nikitopolous et al. 2005). In that study, no effect of cycle phase on female

588 preferences was evident, as females apportioned their mating choices to spread

589 copulations evenly across all the males in their social group. In wild studies female

590 preferences are not so easily isolated from the effects of male aggression. Because such

591 aggression is widespread in primates (Muller \& Wrangham 2009) and other mammals

592 (Clutton-Brock \& Parker 1995), the potential for male coercion must be taken into

593 account before mating preferences can be inferred from female behavior.

\section{Acknowledgements}

596 Research at Kibale was supported by grants from the U.S. National Science

597 Foundation (awards 9807448 and 0416125), the L.S.B. Leakey Foundation, the National

598 Geographic Society, and the Wenner-Gren Foundation. For sponsoring long-term

599 research in Kibale National Park, we thank the Uganda Wildlife Authority and Makerere

600 University Biological Field Station. We thank Gilbert Isabirye-Basuta, John Kasenene,

601 and Jerry Lwanga for their continuing support, and Emily Otali for research oversight. 
602 For assistance in the field we thank the late John Barwogeza, the late Joseph Basagara, 603 Deo Kateeba, Christopher Katongole, Francis Mugurusi, the late Donor Muhangyi, the 604 late Christopher Muruuli, Solomon Musana, Dennis Sebugwawo, and Peter Tuhairwe. 605 Special thanks to Zarin Machanda for assistance with the KCP database. 


\section{References}

607

608 Altmann J (1974) Observational study of behavior: sampling methods. Behav 49:227-267

609

610 Andersson M (1994) Sexual Selection. Princeton University Press, Princeton

611

612 Arcadi AC, Wrangham RW (1999) Infanticide in chimpanzees: review of cases and a

613 new within-group observation from the Kanyawara study group in Kibale National Park.

614 Primates 40:337-351

615

616 Boesch C, Boesch-Achermann H (2000) The Chimpanzees of the Tai Forest: Behavioral

617 Ecology and Evolution. Oxford University Press, Oxford

618

619 Boesch C, Kohou G, Néné H, Vigilant L (2006) Male competition and paternity in wild

620 chimpanzees of the Taï forest. Am J Phys Anthropol 130:103-115

621

622 Brewer Marsden S, Marsden D, Emery Thompson M (2006) Demographic and female

623 life history parameters of free-ranging chimpanzees at the Chimpanzee Rehabilitation

624 Project, River Gambia National Park. Int J Primatol 27:321-410

625

626 Byers JA, Waits L (2006) Good genes sexual selection in nature. PNAS 103:16343-

$627 \quad 16345$

628 
629 Clarke P, Pradhan G, van Schaik CP (2009) Intersexual conflict in primates: Infanticide,

630 paternity allocation, and the role of coercion. In: Muller MN, Wrangham RW (eds) Sexual

631 Coercion in Primates and Humans: An Evolutionary Perspective on Male Aggression

632 against Females. Harvard University Press, Cambridge, MA, pp 42-77

633

634 Clutton-Brock T, McAuliffe K (2009) Female mate choice in mammals. Q Rev Biol $635 \quad 84: 3-27$

636

637 Clutton-Brock TH, Harvey PH (1976) Evolutionary rules and primate societies. In:

638 Bateson PP, Hinde RA (eds) Growing Points in Ethology. Cambridge University Press,

639 Cambridge, pp 195-237

640

641 Clutton-Brock TH, Parker GA (1995) Sexual coercion in animal societies. Anim Behav

$642 \quad 49: 1345-1365$

643

644 Deschner T, Heistermann M, Hodges K, Boesch C (2003) Timing and probability of

645 ovulation in relation to sex skin swelling in wild West African chimpanzees, Pan

646 troglodytes verus. Anim Behav 66:551-560

647

648 Dixson AF (1998) Primate Sexuality: Comparative Studies of the Prosimians, Monkeys,

649 Apes, and Human Beings. Oxford University Press, New York

650

651 Duffy KG, Wrangham RW, Silk J (2007) Male chimpanzees exchange political support 
652 for mating opportunities. Curr Biol 17:586-587

653

654 Emery Thompson M (2005) Reproductive endocrinology of wild female chimpanzees

655 (Pan troglodytes schweinfurthii): methodological considerations and the role of hormones

656 in sex and conception. Am J Primatol 67:137-158

657

658 Emery Thompson M, Wrangham RW (2008) Male mating interest varies with female

659 fecundity in chimpanzees. Int J Primatol 29:885-905

660

661 Emery Thompson M, Muller MN, Kahlenberg S, Wrangham RW (2010). Social and

662 ecological correlates of stress in wild female chimpanzees. Horm Behav 58: 440-449

663

664 Goodall J (1986) The Chimpanzees of Gombe: Patterns of Behavior. Harvard University

665 Press, Cambridge

666

667 Hemelrijk C (1990) A matrix partial correlation test used in investigations of reciprocity

668 and other social interaction patterns at group level. J Theoret Biol 143:405-420

669

670 Hrdy SB (1979) Infanticide among animals: a review, classification, and examination of

671 the implications for the reproductive strategies of females. Ethol Sociobiol 1:13-40

672

673 Hrdy SB (1981) The Woman That Never Evolved. Harvard Press, Cambridge

674 
675 Johnson MH, Everitt BJ (1988) Essential Reproduction. Blackwell Scientific

676 Publications, Oxford

677

678 Kappeler P, van Schaik CP (2004) Sexual selection in primates: review and selective

679 preview. In: Kappeler P, van Schaik CP (eds) Sexual Selection in Primates: New and

680 Comparative Perspectives. Cambridge University Press, Cambridge, pp 3-23

681

682 Matsumoto-Oda A (1999) Female choice in the opportunistic mating of wild

683 chimpanzees (Pan troglodytes schweinfurthii) at Mahale. Behav Ecol Sociobiol 46:258-

$684 \quad 266$

685

686 Mays HLJ, Hill GE (2004) Choosing mates: good genes versus genes that are a good fit.

687 Trends Ecol Evol 19:554-559

688

689 Muller MN (2002) Agonistic relations among Kanyawara chimpanzees. In: Boesch C,

690 Hohmann G, Marchant L (eds) Behavioural diversity in chimpanzees and bonobos.

691 Cambridge University Press, Cambridge, pp 112-124

692

693 Muller MN, Emery Thompson M, Wrangham RW (2006) Male chimpanzees prefer

694 mating with old females. Curr Biol 16:2234-2238

695

696 Muller MN, Kahlenberg SM, Emery Thompson M, Wrangham RW (2007) Male coercion

697 and the costs of promiscuous mating for females chimpanzees. Proc Biol Sci 274:1009- 
700 Muller MN, Kahlenberg SM, Wrangham RW (2009a) Male aggression against females

701 and sexual coercion in chimpanzees. In: Muller MN, Wrangham RW (eds) Sexual

702 Coercion in Primates and Humans: An Evolutionary Perspective on Male Aggression

703 against Females. Harvard University Press, Cambridge, MA, pp 184-217

704

705 Muller MN, Kahlenberg SM, Wrangham RW (2009b) Male aggression and sexual

706 coercion of females in primates. In: Muller MN, Wrangham RW (eds) Sexual Coercion in

707 Primates and Humans: An Evolutionary Perspective on Male Aggression against

708 Females. Harvard University Press, Cambridge, MA, pp 3-22

709

710 Muller MN, Wrangham RW (2004) Dominance, aggression and testosterone in wild

711 chimpanzees: A test of the "Challenge Hypothesis". Anim Behav 67:113-123

712

713 Muller MN, Wrangham RW (2009) Sexual Coercion in Primates and Humans: An

714 Evolutionary Perspective on Male Aggression against Females. In. Harvard University

715 Press, Cambridge, MA

716

717 Murray CM, Wroblewski E, Pusey AE (2007) New case of intragroup infanticide in the

718 chimpanzees of Gombe National Park. Int J Primatol 28:23-37

719

720 Neff BD, Pitcher TE (2005) Genetic quality and sexual selection: an integrated 
721 framework for good genes and compatible genes. Mol Ecol 14:19-38

722

723 Nikitopoulos E, Heistermann M, de Vries H, van Hoof JARAM, Sterck EM. (2005) A

724 pair choice test to identify female mating pattern relative to ovulation in longtailed

725 macaques, Macaca fascicularis. Anim Behav 70:1283-1296

726

727 Nishida T, Kawanaka K (1985) Within-group cannibalism by adult male chimpanzees.

728 Primates 26:274-284

729

730 Nunn CL (1999) The evolution of exaggerated sexual swellings in primates and the

731 graded-signal hypothesis. Anim Behav 58:229-246

732

733 Paul A (2002) Sexual selection and mate choice. Int J Primatol 23:877-904

734

735 Pieta K (2008) Female mate preferences among Pan troglodytes schweinfurthii of

736 Kanyawara, Kibale National Park, Uganda. Int J Primatol 29:845-864

737

738 Roof KA, Hopkins WD, Izard MK, Hook M, Schapiro SJ (2005) Maternal age, parity,

739 and reproductive outcome in captive chimpanzees (Pan troglodytes). Am J Primatol

$740 \quad 67: 199-207$

741

742 Royston J (1982) Basal body temperature, ovulation, and the risk of conception, with

743 special reference to the lifetimes of sperm and egg. Biometrics 38:397-406 
745 Schwensow N, Eberle M, Sommer S (2008) Compatibility counts: MHC-associated mate

746 choice in a wild promiscuous primate. Proc Biol Sci 275:555-564

747

748 Setchell JM (2005) Do female mandrills prefer brightly colored males. Int J Primatol

$749 \quad 26: 715-735$

750

751 Sicotte P (1993) Inter-group encounters and female transfer in mountain gorillas:

752 Influence of group composition on male behavior. Am J Primatol 30:21-36

753

754 Smuts BB, Smuts RW (1993) Male aggression and sexual coercion of females in

755 nonhuman primates and other mammals: evidence and theoretical implications. Adv

756 Study Behav 22:1-63

757

758 Stumpf R (2004) Female Reproductive Strategies in Chimpanzees of the Taï Forest, Côte

759 d'Ivoire. Ph.D. dissertation. Anthropology. Stony Brook University, Stony Brook, NY

760

761 Stumpf R, Boesch C (2005) Does promiscuous mating preclude female choice? Female

762 sexual strategies in chimpanzees (Pan troglodytes verus) of the Taï National Park, Cote

763 d'Ivoire. Behav Ecol Sociobiol 57:511-524

764

765 Stumpf R, Boesch C (2006) The efficacy of female choice in chimpanzees of the Taï

766 Forest, Côte d'Ivoire. Behav Ecol Sociobiol 60:749-765 
768 Swedell L, Schreier A (2009) Male aggression toward females in hamadryas baboons:

769 Conditioning, coercion, and control. In: Muller MN, Wrangham RW (eds) Sexual

770 Coercion in Primates and Humans: An Evolutionary Perspective on Male Aggression

771 against Females. Harvard University Press, Cambridge, MA, pp 244-268

772

773 Tutin CEG (1979) Mating patterns and reproductive strategies in a community of wild

774 chimpanzees. Behav Ecol Sociobiol 6:39-48

775

776 van Noordwijk MA, van Schaik CP (2000) Reproductive patterns in eutherian mammals:

777 adaptations against infanticide? In: van Schaik CP, Janson CH (eds) Infanticide by Males

778 and Its Implications. Cambridge University Press, Cambridge, pp 322-360

779

780 van Schaik CP, Janson CH (2000) Infanticide by Males and its Implications. In.

781 Cambridge University Press, Cambridge, pp 569

782

783 van Schaik CP, Pradhan GR, van Noordwijk MA (2004) Mating conflict in primates:

784 infanticide, sexual harassment and female sexuality. In: Kappeler P, van Schaik CP (eds)

785 Sexual Selection in Primates: New and Comparative Perspectives. Cambridge University

786 Press, Cambridge, pp 131-150

787

788 Wilcox AJ, Weinberg CR, Baird DD (1995) Timing of sexual intercourse in relation to

789 ovulation: effects on the probability of conception, survival of the pregnancy, and sex of 
790 the baby. N Engl J Med 333:1517-1521

791

792 Wrangham RW (2002) The cost of sexual attraction: is there a tradeoff in female Pan

793 between sex appeal and received coercion? In: Boesch C, Hohmann G, Marchant L (eds)

794 Behavioural Diversity in Chimpanzees and Bonobos. Cambridge University Press,

795 Cambridge, pp 204-215

796

797 Wrangham RW, Muller MN (2009) Sexual coercion in humans and other primates:

798 The road ahead. In: Muller MN, Wrangham RW (eds) Sexual Coercion in Primates and

799 Humans: An Evolutionary Perspective on Male Aggression against Females. Harvard

800 University Press, Cambridge, MA, pp 451-468

801

802 Zinner DP, Nunn CL, van Schaik CP, Kappeler PM (2004) Sexual selection and 803 exaggerated sexual swellings of female primates. In: Kappeler P, van Schaik CP (eds)

804 Sexual Selection in Primates: New and Comparative Perspectives. Cambridge University 805 Press, Cambridge, pp 71-8 